cision. This condition is especially important in such work as that of stellar parallax, the determination of the constant of aberration, and wherever the yearly change of temperature may act injuriously. In the selection of better sites for observatories I think we have an easy means of advancing astronomy.

As this science grows and expands, it will become more and more necessary to study the economy of its work, in order that astronomers may bestow their labours in the most advantageous methods, and may rid themselves of all cumbersome and time. consuming processes. The manner of publishing observations has already been much abbreviated, and improved I think, by some of the European astronomers, and this change seems destined to become universal. As the positions of many objects are now well known, the need of printing all the details of the observation, such as the transits of the wires, the readings of the micrometers, \&c., is very slight; and this printing may be safely abandoned. Even this change will lead to a great saving in the time and cost of printing. But this will necessitate a more complete discussion of the work, and a more careful examination of the instruments; things to be desired, since they tend to lift the observer out of his routine, and make him a master of his business. There are objections to this change, and some of them are real, such as the importance of publishing a complete record; but this is overestimated, I think, since the original records ought always to be referred to in case of doubt; and other objections are factitious, such as the need of publishing a large and showy book in order to impose on the public.

We may hope also for improvements in theoretical astronomy, and for the better training and preparation of students of this science. I know that it is sometimes said that theoretical astronomy is finished, and that nothing more can be done. Such assertions come from professors who are old and weary, or from those young men who tire out early in life ; but they are wrong. The improvements that Hansen has made in the theory of perturbations, and Poinsot's study of the theory of rotation, show what careful investigation may do, and assure us of further progress. It must be confessed that some of the astronomical work done in our country bears evidence that the astronomers did not understand the correct methods of reduction, and much of it shows evidence of hasty and ill-considered plans. This is perhaps a natural condition for beginners, but we trust that it has been outgrown. An actual need for the astronomical students of our country is a good book on theoretical astronomy, similar to Pontécoulant's work, in which the whole subject shall be presented in a complete form, such as we find in the "Mécanique Céleste," together with an account of the improvements made by Gauss, Poisson, Hansen, and others. There is no American book of this kind, and the English works are too partial, designed apparently to fit the student for college examinations, and not to give him a complete knowledge of the science. Such a book has hardly been attempted in our language, unless that of Woodhouse may be an exception, and it may be a long time in coming, since it requires a man qualified to do the work, and will involve an expense of labour in the preparation and of cost in publishing such as few are willing to incur. In the mean time it is far better for the student to go directly to the writings of Lagrange and Laplace, of Gauss and Poisson and other masters, rather than to spend time in reading second-rate authors who endeavour to explain them. And generally this will be found the easier way also, since the student avoids the confused notions and symbols, and the grotesque expressions and egotism of small men, and is lifted into the region of ideas and invention.

In presenting his exposition of the nebular hypothesis, which has since become so celebrated, Laplace says: "I present this hypothesis with the distrust which everything ought to inspire that is not a result of observation or of calculation." It is a singular fact that, among all the writings on the nebular hypothesis, I have never seen a reference to this presentation of it by its most distinguished advocate; and yet this is the true spirit of scientific astronomy. Laplace did not wish to exempt his own theories frum criticism, and neither should any one. In astronomy there is no final human authority, no synod or council, but simply an appeal to reason and observation. If a theory or a discovery be true, it will stand the test of observation and of calculation; if false, it must pass away to that Miltonian limbo where so many things have gone and are going. The question is sometimes asked, Of what use is astronomy? and the reply generally made is that it has conferred great benefits on navigation and on commerce, since it is by means of his astronomical knowledge that the sailor determines the position of his ship on the ocean. There is a truth in this reply, but it is only partial. The great value of astronomy is that it is really a science and that it has broken the path and led the way through which all branches of science must pass if they ever become scientific. It is the spirit of honest, unrelenting criticism, and of impartial examination, that finally eliminates error and awards to every one his just due, that makes astronomy honourable and attractive ; and it is by cultivating this spirit that astronomy confers its chief benefit, for it is this that shall break in pieces and destroy all false assumptions in science and in philosophy.

\section{SCIENCE IN NORWAY}

$W^{E}$ have received several publications from Norway of scientific interest.

Nyt Magazin for Naturvidenskaberne. B. 25, H. 4.

\section{(Kristiania, 1880.)}

In this number of the Norwegian "New Magazine for Natural Sciences" Herr Hansen continues his description of the annelids yielded by the Norwegian North Sea Expedition of $x 878$, to which he appends drawings of his own of all the rarer forms.-Herr L. Schmelck gives the results of bis analysis of sea-water obtained in the same voyage within and near the Polar circle. The water was taken at various depths, and was obtained from a stratum intermediate between the surface and the bottom by means of an apparatus devised for the purpose by Herr Tornöe.-Herr Brögger and Reusch's observations on the character and localities of Norwegian apatite, which originally appeared in 1875 in the Zeitschrift d. deutschen geologischen Gesellschaft, are here translated into Norwegian by the authors, who have made various additions to their paper, which is illustrated with numerous drawings. - In a paper on the Lepidoptera of Norway by W. M. Schöyen the author draws attention to the number of new forms added to this branch of the Norwegian fauna since the publication, in 1876 , of Siebke's list of the insects of Norway. The number given at that time for the lepidoptera was 934 ; it is now raised to 1 ,org. The writer's own contribution to these is 38 hitherto undetected Norwegian species, the habitats and characters of which he describes.

Kort Fremstilling af de Norske Kursteders Udvikling, \&c. Ved Axel Lund, M.D. (Kristiania, 1880.)--In this brochure we are reminded that Norway, from her geognostic character, is naturally deficient in thermic springs, and we are shown that till recently the water-cure-taking the words in a comprehensive sense to include the use of waters internally and externally-was unknown in the country. In fact even now the Norwegians stand exceptionally low in the scale of water-using nations, although an encouraging change in this respect has been manifested of late years by the establishment of mineral and sea-bathing places in various parts of the kingdom. These Dr. Lund describes at great length, giving the analysis of the waters yielded by the few springs that have been opened, and the amount of salt present in the sea-water at the various marine stations, with the medical reports of each and the mode of treatment adopted. In the last respect the only difference that we observe from the system generally followed at German baths is that at the seabathing establishment in the Sandefjord, a small species of Medusa is used to excite local irritation in cases of cerebrospinal, rheumatic, or neuralgic affections, by passing the animals rapidly over the $\mathrm{p}^{\text {nrts }}$ affected. To Dr. Thaulow, the founder of the baths at the Sandefjord and at Modum, the Norwegians owe a large debt of gratitude as the first of their countrymen who drew public attention to the paramount importance of baths as a hygienic agent. Sweden has long been in advance of Norway in its appreciative comprehension of the curative value of mineral and sea waters; and from Dr. Lund the reader will learn all that there is to learn in regard to the water-establishments, springs, and baths of the sister kingdom, while he may also gather some information respecting similar institutions in the Danish dominions. In conclusion, we may observe that some of the newly-opened Norweglan water-cure establishments, as that of Modum, lying in the midst of pine-woods, and the sea-bathing places on the Sandefjord and Kristianiafjord, offer numerous attractions to foreigners in respect to salubrity of air, beauty of position, and moderate cost of living.

Knudshö, eller Fjeldforaen. J. B. Barth. (Kristiania, 1880.) - Herr Barth, who is well known for his animated descriptions of the natural scenery of his country, and his lively narrative of 
the adventures of a sportsman in Norway, supplies us in the present sketch with a comprehensive résume of the flora of the Fjelds. The spot he has chosen for his point of observation is the donble-topped hill Knudshö, near Kongsvold, well known to the botanists of other countries, as well as to those of Norway, for its exceptionally rich and varied Alpine flora. Here may be gathered the rare Artemisia norvegica; the gentians, nivalis and glacialis; some of the less common saxifrages, numerous species of Carex and Salix; and some Alpine forms, as Kobresia caricina, Chamaropes alpina, which are not found elsewhere so low down; while here, too, the collector will find close at hand a number of sub-Alpine and south-Norwegian plants of rare occurrence in other parts of the country. Herr Barth, himself an enthusiastic botanist and a practised collector, never fails to give the local and ordinary Norwegian name of the plant he describes, in addition to its scientific designation; and thus supplies foreigners with very valuable and much-needed information, the want of which often proves to be a matter of great inconvenience in studying the flora of a foreign country.

Om Grantörken og Barkbillen. J. B. Barth.-In this little pamphlet the author, who is one of the first authorities in Norway on questions of forestry and arboriculture generally, explains his reasons for differing from the opinion commonly received, that the desiccation and ultimate death of the Norwegian spruce (Abies excelsa) are due to the attacks of Tomicus typographus (Bostrychus typographus), which is usually regarded as the most pernicious of all the insect-enemies of the Coniferæ. Herr Barth does not dispute the fact that this beetle is to be found often in large numbers on trees affected by abnormal drying up, whether still standing or cut down; but, in his opinion, although disease in the tree may be the cause, it is not the result of the presence of the Tomicus, which he believes to have absolutely no effect on the condition of the bark. According to this view the numerous agents employed in Germany and elsewhere to eradicate this beetle have no result but waste of labour and money; the only remedy against the drying up of the bark being a more scientific mode of clearing forests, in which the trees often perish either through overcrowding, or more frequently through reckless felling, by which cold blasts are allowed to fall directly on the interior. Herr Barth's views are in opposition to those of the majority of the working foresters of Germany and Scandinavia, but his extensive acquaintance with home and foreign forests, his great practical experience, and his reputation as a naturalist, entitle them to all possible respect, although it is not to be supposed that his plea for the innocuousness of the Bostrychus typographus will be admitted without much sifting of the evidence, seeing that this insect is generally believed by German foresters to have been the cause of the destruction of the forests of the Harz Mountains, when between 1780 and 1790 two million trees died of desiccation.

\section{SPECTROSCOPIC INVESTIGATIONS}

$A S$ I have stated in my former communication, ${ }^{2}$ all chemically related elements exhibit a homology of spectra, the various spectra of the elements of a group differing solely in the manner in which their groups of lines are shifted towards one end or other of the spectrum.

In a comparative investigation on the alkaline earths, $I$ have arrived at conclusions which may explain these remarkable analogies in chemically-related elements.

I have now the honour of laying before the Academy a brief account of my investigations; on another occasion I shall report on this subject more fully.

If the spectra of the alkaline earths are produced by a jar. spark in a hydrogen-atmosphere, ${ }^{3}$ spectra are obtained which show the homology of the spectral lines very beautifully. The spectrum of magnesium cannot be compared with the spectra obtained in this manner, because it does not contain the less refrangible lines. However, without the jar, or employing a smaller battery and a smaller induction-coil, it appears that in the spectra of calcium and strontium all lines in the red and yellow disappear, and the spectra which become visible are remarkably similar to those of magnesium.

${ }^{I}$ By G. Ciamician, in Sitz. Ber, der k. Akad. der Wiss., Vienna, Vol, Ixxiv. Heft i.

2 "Ueber die Spectren der chemischen Elemente und ihrer Verbindungen" (vol. lxxvi, chapter ii., October, 1877). "Ueber den Einfluss der Dichte und der Temperatur auf die Spectren von Dämpfen und Gasen." (vol. Ixxviii. chapter ii., October, 1878 .)

3 With four of six medium Bunsen's elements and a great Gaiffe's induction coil giving a spark of to centimetres.
Comparing the less refrangible part of the spectrum of the alkaline earths, which are only rendered visible by increased temperature with the less refrangible half of the entire oxygen spectrum, we find the remarkable fact that these two halves of the spectra show a decided resemblance or homology. From this we may conclude that the spectrum of the groups of the earth-alkali metals is composed of the spectrum of magnesium and of that of the less refrangible parts of oxygen.

In order to determine the real importance of these remarkable analogies-it being known that the atomic weights of baryum, strontium, and calcium are capable of being composed of the atomic weights of magnesium and oxygen ${ }^{1}-\mathrm{I}$ found it necessary to analyse the spectra of combinations, which are not saturated, but behave as compound radicals, and thus most resemble in chemical behaviour the simple radicals or elements.

Hitherto I have analysed cyanogen and carbonic oxide. The cyanogen spectrum comprises two portions, one of which is the homologue of the nitrogen spectrum, the other the homologue of the less refrangible part of the earbon spectrum.

Also in the carbonic oxide spectrum there are present the well-known groups of carbon appearing as bands, and displaced in the red field there are several lines homologous to those of oxygen. Therefore the same relation exists between the spectra of nitrogen and carbon, and between the spectra of cyanogen, carbon, and oxygen, and carbon oxide spectrum, which prevails between the spectra of magnesium and oxygen and the spectra of the earth-alkali metals.

One can go further and say that in general the homology of the spectral lines of chemically-related elements is in all probability based upon the circumstance that the elements of such natural groups conform to the laws of Mendelejeff on atom. weights, and consist of identical components.

\section{UNIVERSITY AND EDUCATIONAL}

\section{INTELLIGENCE}

CAMERIDge.-The Science Lectures at Cambridge this term include Prof. Liveing on the General Principles of Chemistry, and on Spectroscopic Analysis; and Prof. Dewar on Physical Chemistry. One of the demonstrators will give demon trations in Volumetric Analysis; and Mr. Scott, assistant to Prof. Dewar, will give a course of demonstrations in Elementary Organic Chemistry. For permssion to carry out special investigations in the University laboratories application should be made to one of the Professors.

Lord Rayleigh will lecture on Galvanic Electricity and ElectroMagnetism in the Cavendish Laboratory; Dr. Schuster will lecture weekly on Radiation; Mr. Glazebrook will give an elementary course of demonstrations in Electricity and Magnetism; and Mr. Shaw will give demonstrations on the Principles of Measurement and the Physical Properties of Bodics. Courses of demonstrations are announced for the Lent Term on Heat and Advanced Electricity and Magnetism; and for the Easter Term on Light, Elasticity, and Sound.

Mr. W. J. Lewis will lecture on the Silicates, in the [Mineralogical Lecture-room.

Mr. F. M. Balfour will give elementary and advanced courses on the Morphology of Invertebrata, with practical work. Prof. Humphry will lecture on the Osseous System; Prof. Hughes on the Principles of Geology, with Field Lectures; Prof. Latham on Therapeutics; Prof. Newton on Invertebrata ; Prof. Stuart on Mechanism.

It is to be hoped that something may be done this term to relieve science students in the marter of Greek, and to encourage French and German studies, for want of which there is so much hindrance to science, as well as literature. The Sedgwick Geological Museum, with money accumulating, must still wait, wo suppose. Will the Museum be ready for 1900 ?

Mr. Sedley Taylor will lecture on the Acoustics of Music in the Cavendish Laboratory.

\section{SCIENTIFIC SERIALS}

Bulletins de la Societé d' Anthropologie de Paris, tome iii. fasc. 2 (1880). - M. Robin, Inspecteur primaire du Département de Loiret-Cher, has laid before the Society his scheme for obtaining important anthropological measurements by the help of teachers of schools. The proposed questions, with a full description of the various appliances by which such measurements could be

I It is, namely, $24+x 6=40$ (calcium), $24+4 \times 16=88$ (strontium), and $24+\mathrm{r}_{7} \times 16=\mathrm{r}_{3} 6$ (barium). 